\title{
Continuous 5-fluorouracil infusion plus long acting octreotide in advanced well-differentiated neuroendocrine carcinomas. A phase II trial of the Piemonte Oncology Network
}

\author{
Maria P Brizzi ${ }^{1}$, Alfredo Berruti ${ }^{1}$, Anna Ferrero ${ }^{1}$, Enrica Milanesi ${ }^{3}$, \\ Marco Volante ${ }^{2}$, Federico Castiglione ${ }^{4}$, Nadia Birocco ${ }^{3}$, Sebastiano Bombaci ${ }^{5}$, \\ Davide Perroni ${ }^{6}$, Benedetta Ferretti ${ }^{7}$, Oscar Alabiso ${ }^{8}$, Libero Ciuffreda ${ }^{3}$, \\ Oscar Bertetto ${ }^{3}$, Mauro Papotti ${ }^{2}$ and Luigi Dogliotti*1
}

Address: ${ }^{1}$ Oncologia Medica, Dipartimento di Scienze Cliniche e Biologiche, Università di Torino, Azienda Ospedaliera San Luigi, Regione Gonzole, 10, 10043 Orbassano (TO), Italy, ${ }^{2}$ Anatomia Patologica, Dipartimento di Scienze Cliniche e Biologiche, Università di Torino, Azienda Ospedaliera San Luigi, Regione Gonzole, 10, 10043 Orbassano (TO), Italy, ${ }^{3}$ Centro Oncologico Ematologico Subalpino, Azienda Ospedaliera Molinette, Corso Bramante, 88, 10126 Torino, Italy, ${ }^{4}$ Oncologia Medica, Ospedale San Lazzaro, Via Pierino Belli, 26, 12051 Alba (CN), Italy, ${ }^{5}$ Oncologia Medica, Ospedale di Ivrea, P. Della Credenza, 2, 10015 Ivrea (TO), Italy, ${ }^{6}$ Oncologia Medica, Ospedale Civile di Saluzzo, Via Spielberg, 58, 12037 Saluzzo (CN), Italy, ${ }^{7}$ Oncologia Medica, Ospedale "B. Eustacchio", Via Del Glorioso, 8, 62027 San Severino Marche (MC), Italy and ${ }^{8}$ Oncologia Medica, Azienda Ospedaliera "Maggiore della Carità", Corso Mazzini, 18, 28100 Novara, Italy

Email: Maria P Brizzi - mariapia.brizzi@email.it; Alfredo Berruti - alfredo.berruti@gmail.com; Anna Ferrero - anna.ferrero80@gmail.com; Enrica Milanesi - enricami@libero.it; Marco Volante - marco.volante@unito.it; Federico Castiglione - fcastiglione@inwind.it; Nadia Birocco - n.birocco@libero.it; Sebastiano Bombaci - sebastianobomba@libero.it; Davide Perroni - davide.perroni@asl17.it; Benedetta Ferretti - alesianif@libero.it; Oscar Alabiso - poloncno@maggioreosp.novara.it; Libero Ciuffreda - lciuffreda@molinette.piemonte.it; Oscar Bertetto - obertetto@molinette.piemonte.it; Mauro Papotti - mauro.papotti@unito.it; Luigi Dogliotti* - luigi.dogliotti@unito.it

* Corresponding author

Published: 3 November 2009

BMC Cancer 2009, 9:388 doi:10.1186/147I-2407-9-388
Received: 16 December 2008

Accepted: 3 November 2009

This article is available from: http://www.biomedcentral.com/I47I-2407/9/388

(c) 2009 Brizzi et al; licensee BioMed Central Ltd.

This is an Open Access article distributed under the terms of the Creative Commons Attribution License (http://creativecommons.org/licenses/by/2.0), which permits unrestricted use, distribution, and reproduction in any medium, provided the original work is properly cited.

\begin{abstract}
Background: Well-differentiated neuroendocrine carcinomas are highly vascularized and may be sensitive to drugs administered on a metronomic schedule that has shown antiangiogenic properties. A phase II study was designed to test the activity of protracted 5-fluorouracil (5FU) infusion plus long-acting release (LAR) octreotide in patients with neuroendocrine carcinoma.

Methods: Twenty-nine patients with metastatic or locally advanced well-differentiated neuroendocrine carcinoma were treated with protracted $5 \mathrm{FU}$ intravenous infusion $\left(200 \mathrm{mg} / \mathrm{m}^{2}\right.$ daily) plus LAR octreotide ( $20 \mathrm{mg}$ monthly). Patients were followed for toxicity, objective response, symptomatic and biochemical response, time to progression and survival.

Results: Assessment by Response Evaluation Criteria in Solid Tumors (RECIST) criteria showed partial response in 7 (24.1\%), stable disease in 20 (69.0\%), and disease progression in 2 patients. Response did not significantly differ when patients were stratified by primary tumor site and proliferative activity. A biochemical (chromogranin A) response was observed in 12/25 assessable patients (48.0\%); symptom relief was obtained in $9 / 15$ symptomatic patients $(60.0 \%)$. There was non significant decrease in circulating vascular epithelial growth factor (VEGF) over time. Median time to progression was 22.6 months (range, 2.7-68.5); median overall survival was not reached yet. Toxicity was mild and manageable.
\end{abstract}




\begin{abstract}
Conclusion: Continuous/metronomic 5FU infusion plus LAR octreotide is well tolerated and shows activity in patients with well-differentiated neuroendocrine carcinoma. The potential synergism between metronomic chemotherapy and antiangiogenic drugs provides a rationale for exploring this association in the future.
\end{abstract}

\title{
Trial registration: NCT00953394
}

\section{Background}

Well-differentiated neuroendocrine carcinomas are a group of rare malignancies generally characterized by low aggressiveness [1-4]. Surgery is the only curative modality. In unresectable disease, somatostatin analogues effectively reduce hormonal hypersecretion, but tumor shrinkage is only rarely seen ( $0 \%-6 \%$ of patients) $[5,6]$.

Because of their low proliferative activity, conventional chemotherapy for these tumors is not recommended [79]. Metronomic chemotherapy, i.e., the frequent administration of cytotoxic drugs at low doses [10], has demonstrated antiangiogenetic properties [11-13]. Since welldifferentiated neuroendocrine carcinomas are highly vascular $[14,15]$, there is a rationale for testing metronomic chemotherapy in this clinical setting [16].

Five-fluorouracil (5FU) is frequently employed in the treatment of advanced neuroendocrine carcinoma [1719]. The combination of protracted 5FU infusion and alfa 2b interferon has been tested in the treatment of well-differentiated neuroendocrine carcinomas of the gastroenteropancreatic tract, and a disease response obtained in more than $40 \%$ of patients [20]. Moreover, concomitant administration of somatostatin analogues to enhance the effect of the antiproliferative activity of 5FU has been reported in several in vitro and in vivo preclinical studies [21].

On these grounds, the Piemonte Region Oncology Network conducted a multicenter phase II trial to assess the activity and safety profile of a combination regimen of protracted 5FU infusion and long-acting release (LAR) octreotide in patients with advanced well-differentiated neuroendocrine carcinomas. The primary study aim was to assess response to treatment; the secondary aims were to evaluate toxicity, biochemical and symptomatic response, time to progression and survival.

\section{Methods}

\section{Study population}

Eligibility criteria included histological diagnosis of welldifferentiated neuroendocrine carcinoma according to the World Health Organization (WHO) classification [1], locally advanced or metastatic disease not amenable to surgery with radical intent, at least one measurable target lesion, radiological documentation of progressive disease, somatostatin receptor scintigraphy, Eastern Cooperative Oncology Group (ECOG) performance status grade $\leq 2$, life expectancy $\geq 12$ weeks, adequate bone marrow reserve (WBC count $\geq 3.5 \times 10^{9} / \mathrm{L}$, platelets $\geq 100 \times 10^{9} / \mathrm{L}$, hemoglobin $\geq 10 \mathrm{~g} / \mathrm{dL}$ ), adequate hepatic and renal function (hepatic enzymes and bilirubin $<2 \times$ upper limit of normal, serum creatinine $<1.4 \mathrm{mg} / \mathrm{dl}$ ). Exclusion criteria were non-malignant systemic disease or conditions that precluded patients from receiving the study therapy, second primary malignancies, and previous systemic antineoplastic treatment including somatostatin analogues.

Diagnostic work-up included physical examination, screening chemistry, circulating chromogranin A (CgA), abdominal, chest and pelvis computed tomography (CT), and somatostatin receptor scintigraphy. The study was approved by the local ethic committee of each participating center. Written informed consent was obtained from all patients before starting treatment.

\section{Histology and immunohistochemical analysis}

The histological diagnoses performed at each center were centrally reviewed by two experienced pathologists using the proposed morphological criteria for well-differentiated neuroendocrine carcinoma [1]. In addition, immunohistochemical analysis of the Ki-67 proliferation index (DakoCytomation, Glostrup, Denmark, clone MIB-1, diluted 1/300), type 2 somatostatin receptor expression (BioTrend, Cologne, Germany, code SS-800, diluted 1/ 3000) and VEGF marker levels (NeoMarkers, Fremont, CA, USA, polyclonal, diluted 1/250) was performed.

\section{Treatment plan and toxicity assessment}

LAR octreotide acetate at a dose of $20 \mathrm{mg}$ was administered intramuscularly every 4 weeks. The first administration was matched to an induction treatment of octreotide (0.1 mg subcutaneous every $8 \mathrm{~h}$ ) for 14 days; $5 \mathrm{FU}$ was given as a protracted continuous infusion without interruption at a daily dose of $200 \mathrm{mg} / \mathrm{m}^{2}$ of body-surface area through an elastomeric pump connected to a central venous access.

5FU treatment was planned to be administered for 6 months, however, prolonged 5FU administration beyond 6 months was permitted. LAR octreotide administration was continued until disease progression. 
Toxicity was assessed according to National Cancer Institute Common Toxicity Criteria (NCI CTC) [22].

5FU dose modifications were performed as follows: if WBC count was $<2500 / \mathrm{mL}$ and/or platelet count < $100,000 / \mathrm{mL}$, $5 \mathrm{FU}$ was delayed for 1 week. If the blood count did not recover, then 5FU was delayed for a further week and the dose reduced by $25 \%$. In the event of severe plantar-palmar erythema with blistering and desquamation, 5FU was interrupted until healing had occurred. In the event of persistent diarrhea and/or grade 2 mucositis, $5 \mathrm{FU}$ was discontinued for 1 week. If grade 3/4 diarrhea and mucositis occurred, 5FU was withdrawn until recovery then resumed at a dose reduced by $25 \%$.

\section{Response evaluation}

A CT scan was performed every 12 weeks after initiation of treatment. Disease response was evaluated according to RECIST criteria [23].

Symptomatic patients were asked to keep a diary where they reported frequency and duration of disease-related symptoms. CR was defined as the complete relief of all symptoms and PR as a reduction of at least $50 \%$ in both the frequency and intensity of symptoms.

Circulating CgA was measured every 3 months using a commercially available assay (DAKO ELISA, DAKO A/S, Glostrup, Denmark). A decline in CgA levels was considered a biochemical response and defined as either a CR if the tumor marker level returned to normal or as a PR if tumor marker levels decreased by $50 \%$ or more. An increase of more than $25 \%$ in CgA levels was defined as biochemical progression.

Circulating VEGF levels were retrospectively assessed using a sandwich enzyme immunoassay technique with a monoclonal antibody specific for VEGF (R\&D System Europe, Abingdon, UK) in plasma samples collected at baseline and after 3 and 6 months in 11 patients, all recruited at the study coordinating center (San Luigi Hospital, Orbassano, Torino).

\section{Statistical analysis}

The primary end point of the study was the response rate. A Simon two-stage design [24] was used to test the null hypothesis that the true objective response rate was < $10 \%$. The upper limit of first-step drug rejection was 1 response (CR or $\mathrm{PR}$ ) in the first 10 consecutive patients; the upper limit of second-step rejection was 5 responses in 29 consecutively enrolled patients. Time to progression (TTP) and overall survival (OS) were assessed using the Kaplan-Meier product limit estimate method. The rates of TTP and OS were measured from the date of treatment start to the date of progression and the date of last follow- up or death, respectively. A Cox proportional-hazards regression analysis was used to assess in multivariate analysis the prognostic role of mitosis count and Ki67 expression. Changes in VEGF levels over time were assessed by the Friedman analysis of variance for non parametric matched paired data. P values $<0.05$ were considered statistically significant. Statistical analyses were performed using the Statistica/PC software program (Statsoft, Tulsa OK, USA).

\section{Results}

\section{Patient characteristics}

Twenty-nine patients with locally advanced or metastatic disease with radiological documentation of progressive disease were entered into the study at the seven participating centers from 2004 to 2006. The baseline patient characteristics are depicted in Table 1. No patients had received any previous systemic antineoplastic treatment including somatostatin analogues. None had received radionuclide therapy before entry into the study.

A diagnosis of well-differentiated neuroendocrine carcinoma was confirmed in 28 patients by central histological review. One patient had a poorly differentiated carcinoma and was therefore ineligible. However, according to the intent-to-treat principle, this patient was included in the analyses.

\section{Treatment and toxicity}

5FU treatment was administered for a median duration of 6 months (range, 2-9). Twenty-three patients (79.3\%) completed the scheduled 6-month 5FU treatment. Six patients interrupted earlier because of disease progression ( 2 cases), patient decision ( 1 case), radionuclide therapy ( 2 cases), and surgical debulking to control an insulinoma syndrome (1 case). Associated side effects were mild (Table 2). No hematologic grade III-IV events were recorded. Grade II-III mucositis and diarrhea occurred in 3 patients (10.3\%). Two patients $(6.9 \%)$ developed grade III hand-foot syndrome. 5FU administration was delayed for at least 1 week in 8 patients $(27.6 \%)$ and for 2 weeks in 3 patients $(10.3 \%)$. The reasons for the delayed course were hematological in 1 patient and non-hematological (mucositis, diarrhea, cutaneous) in the other 10 cases. $5 \mathrm{FU}$ infusion was reduced by $75 \%$ in 2 patients due to old age and grade III diarrhea and reduced by $50 \%$ in 1 patient due to grade III mucositis.

\section{Treatment activity}

Seven patients attained a PR (24.1\%), 20 SD (69.0\%), and $2(6.9 \%)$ progressed (Table 3$)$. Disease responses were observed in patients with liver ( 5 patients) and lymph node metastasis (2 patients). 
Table I: Patient characteristics

\begin{tabular}{|c|c|}
\hline Patients & $\mathbf{N}=\mathbf{2 9}$ \\
\hline Median age (range) - yrs & $59(26--80)$ \\
\hline \multicolumn{2}{|l|}{ Gender -- no. (\%) } \\
\hline Male (\%) & $15(52.0)$ \\
\hline Female (\%) & $14(48.0)$ \\
\hline \multicolumn{2}{|c|}{ ECOG performance status -- no. (\%) } \\
\hline 0 & II (37.9) \\
\hline I & $17(58.6)$ \\
\hline 2 & $\mathrm{I}(3.5)$ \\
\hline \multicolumn{2}{|c|}{ Primary tumor site -- no. (\%) } \\
\hline Pancreas & $13(44.8)$ \\
\hline Functioning & $5(17.2)$ \\
\hline Unknown & $7(24.2)$ \\
\hline Small bowel & $7(24.2)$ \\
\hline Appendix & I (3.4) \\
\hline Colon & $\mathrm{I}(3.4)$ \\
\hline \multicolumn{2}{|l|}{ Tumor Stage -- no. (\%) } \\
\hline Locally advanced/metastatic & $2 / 27$ \\
\hline \multicolumn{2}{|l|}{ Site of metastases -- no. (\%) } \\
\hline$<2$ sites & $13(44.8)$ \\
\hline$\geq 2$ sites & $16(55.2)$ \\
\hline \multicolumn{2}{|l|}{ Prior therapies -- no. (\%) } \\
\hline Surgery & $9(31.0)$ \\
\hline Progressive disease & $29(100)$ \\
\hline \multicolumn{2}{|c|}{ Baseline symptoms -- no. (\%) } \\
\hline Diarrhea & $6(20.6)$ \\
\hline Flushing & $4(13.8)$ \\
\hline Carcinoid syndrome & $4(13.8)$ \\
\hline Hypoglycemia & $2(6.9)$ \\
\hline Others & $10(34.5)$ \\
\hline \multicolumn{2}{|c|}{ Circulating chromogranin A levels (U/L) - no. (\%) } \\
\hline Normal levels & $4(13.8)$ \\
\hline Supranormal levels & $25(86.2)$ \\
\hline \multicolumn{2}{|c|}{$\begin{array}{l}\text { Histological tumor characteristics -- no. (\%) } \\
\text { SST2 }\end{array}$} \\
\hline $1+$ & $2(9.1)$ \\
\hline $2+$ & $8(36.4)$ \\
\hline $3+$ & $12(54.5)$ \\
\hline missing & 7 \\
\hline \multicolumn{2}{|c|}{ Mitosis (per square millimeter) } \\
\hline$<2$ & $17(68.0)$ \\
\hline $2-20$ & $7(28.0)$ \\
\hline$>20$ & I $(4.0)$ \\
\hline missing & 4 \\
\hline \multicolumn{2}{|l|}{ Ki67 } \\
\hline$\leq \mathbf{2} \%$ & II (42.3) \\
\hline $3-10 \%$ & $13(50.0)$ \\
\hline$>10 \%$ & $2(7.7)$ \\
\hline missing & 3 \\
\hline \multicolumn{2}{|l|}{ VEGF } \\
\hline 0 & $3(15.8)$ \\
\hline I & $4(21.1)$ \\
\hline 2 & $7(36.8)$ \\
\hline 3 & $5(26.8)$ \\
\hline missing & 10 \\
\hline
\end{tabular}

SST2 = somatostatin receptor type 2

VEGF = vascular endothelial growth factor 
Table 2: Treatment-related toxicity.

\begin{tabular}{llll}
\hline Higher grade WHO toxicity & $\begin{array}{l}\text { N= 29 } \\
\text { No. (\%) }\end{array}$ & $\begin{array}{l}\text { N=29 } \\
\text { No. (\%) }\end{array}$ & $\begin{array}{l}\text { N = 29 } \\
\text { No. (\%) }\end{array}$ \\
\hline & I & $\mathbf{2}$ & $\mathbf{3}$ \\
Anemia & -- & $2(6.9)$ & -- \\
Thrombocytopenia & $\mathrm{I}(3.4)$ & -- & -- \\
Neutropenia & $2(6.9)$ & $2(6.9)$ & -- \\
Asthenia & $9(31.0)$ & $2(6.9)$ & -- \\
Nausea-vomiting & $7(24.1)$ & $\mathrm{I}(3.4)$ & -- \\
Diarrhea & $16(55.1)$ & $2(6.9)$ & $\mathrm{I}(3.4)$ \\
Hand-foot syndrome & $4(13.8)$ & $4(13.8)$ & $2(6.9)$ \\
Mucositis & $4(13.8)$ & $2(6.9)$ & $\mathrm{I}(3.4)$ \\
\hline
\end{tabular}

Biochemical and symptomatic response was obtained in $48 \%$ and $60 \%$ of patients, respectively. After medical treatment, surgery was carried out in 3 patients: 1 with a PR and 2 with SD (minimal tumor shrinkage <20\%). One patient was operated for surgical removal of a primary pancreatic tumor and chemoembolization of liver metastases; 1 patient underwent right hemicolectomy plus intraoperative radiofrequency ablation of liver metastases, 1 patient underwent radical excision of a primary pancreatic tumor and liver metastases. Disease response did not change when the patients were stratified by primary disease site, mitotic count and Ki67.

In the 11 patients with circulating VEGF assessed before and after treatment, there was a non significant trend of progressive marker reduction over time (mean VEGF levels 147,96 , and $67 \mathrm{pg} / \mathrm{ml}$ at baseline, 3 and 6 months, respectively, $\mathrm{P}=0.33$ ). VEGF decreased $>50 \%$ from baseline in 5 patients, between 25 and $50 \%$ in $2,<25 \%$ in 2 , and increased $>25 \%$ in 2 .

\section{Predictors of patient outcome}

At the last follow-up evaluation, 16 (55.2\%) patients showed disease progression and $7(24.1 \%)$ had died; the median duration of follow-up was 51 months.
The median TTP of all 29 patients was 22.6 months (range, 2.7-68.5), while the median OS was not reached. After 2 years, $48 \%$ of patients were free from progression and $82 \%$ were alive. In the univariate analysis, Ki67 immunostaining at a cutoff value $\leq 2 \%$ and mitotic count at a cutoff value $<2 \%$ were predictors of either TTP $(\mathrm{P}<$ 0.005 and $\mathrm{P}<0.003)$ or OS $(\mathrm{P}=0.06$ and $\mathrm{P}=0.004)$ (Figure 1 ), while age, sex, patient performance status, primary disease site and VEGF expression were not. In the multivariate analysis, Ki67 (continuous variable) but not mitotic count was an independent predictor of either disease recurrence (hazard ratio [HR] 1.03, 95\% confidence interval [CI] 1.00-1.06; $\mathrm{P}=0.05$ ) or death (HR 1.04, 95\% CI 1.00-1.08; $\mathrm{P}<0.04)$. Of the 3 patients who underwent surgery after treatment, only 1 patient progressed after 20.0 months. The remaining 2 patients were alive and free from progression after 29.7 and 35.1 months, respectively.

\section{Discussion}

In this multicenter phase II trial, protracted 5-fluorouracil (5FU) infusion administered in combination with LAR octreotide was an active regimen in the upfront treatment of advanced neuroendocrine carcinomas. This regimen was associated with an overall objective response rate of $24 \%$, a biochemical response rate of $48 \%$, and a symptomatic response rate of $60 \%$. To our knowledge, this is the first trial to test the activity of the combination of octreotide and a chemotherapy drug in somatostatin-naïve patients. Due to the rarity of neuroendocrine tumors, this trial was not randomized and this represents a limitation. Nonetheless, the objective response rate obtained here seems to be higher than that expected with somatostatin alone $(0-6 \%)[4,8,25]$. The recently presented results of the first randomized study testing the efficacy of octreotide versus placebo in metastatic well-differentiated neuroendocrine carcinoma showed that octreotide was superior to placebo in prolonging time to progression, despite a comparable response rate [26]. These data further confirm that the antineoplastic activity of somatastatin analogues is not due to tumor shrinkage but rather to

Table 3: Response to treatment

\begin{tabular}{llll}
\hline & $\begin{array}{l}\text { Clinical response } \\
\text { (RECIST) } \\
\mathbf{N = 2 9} \\
\text { No. (\%) }\end{array}$ & $\begin{array}{l}\text { Biochemical response (Chromogranin A) } \\
\mathbf{N}=\mathbf{2 5} \\
\text { No. (\%) }\end{array}$ & $\begin{array}{l}\text { Symptomatic response } \\
\mathbf{N}=\mathbf{1 5} \\
\text { No. (\%) }\end{array}$ \\
\hline Progression & $2(6.9)$ & $2(8.0)$ & $6(40.0)$ \\
No change & $20(69.0)$ & $11(44.0)$ & $6(40.0)$ \\
Partial response & $7(24.1)$ & $8(32.0)$ & $3(20.0)$ \\
Complete response & - & $4(16.0)$ & $9(60.0)$ \\
Overall response & $7(24.1)$ & $12(48.0)$ & \\
& $(95 \% \mathrm{Cl} \mathrm{8.3-39.9)}$ & $(95 \% \mathrm{Cl} 28.0-68.0)$ & \\
\hline
\end{tabular}

RECIST $=$ Response Evaluation Criteria in Solid Tumors 

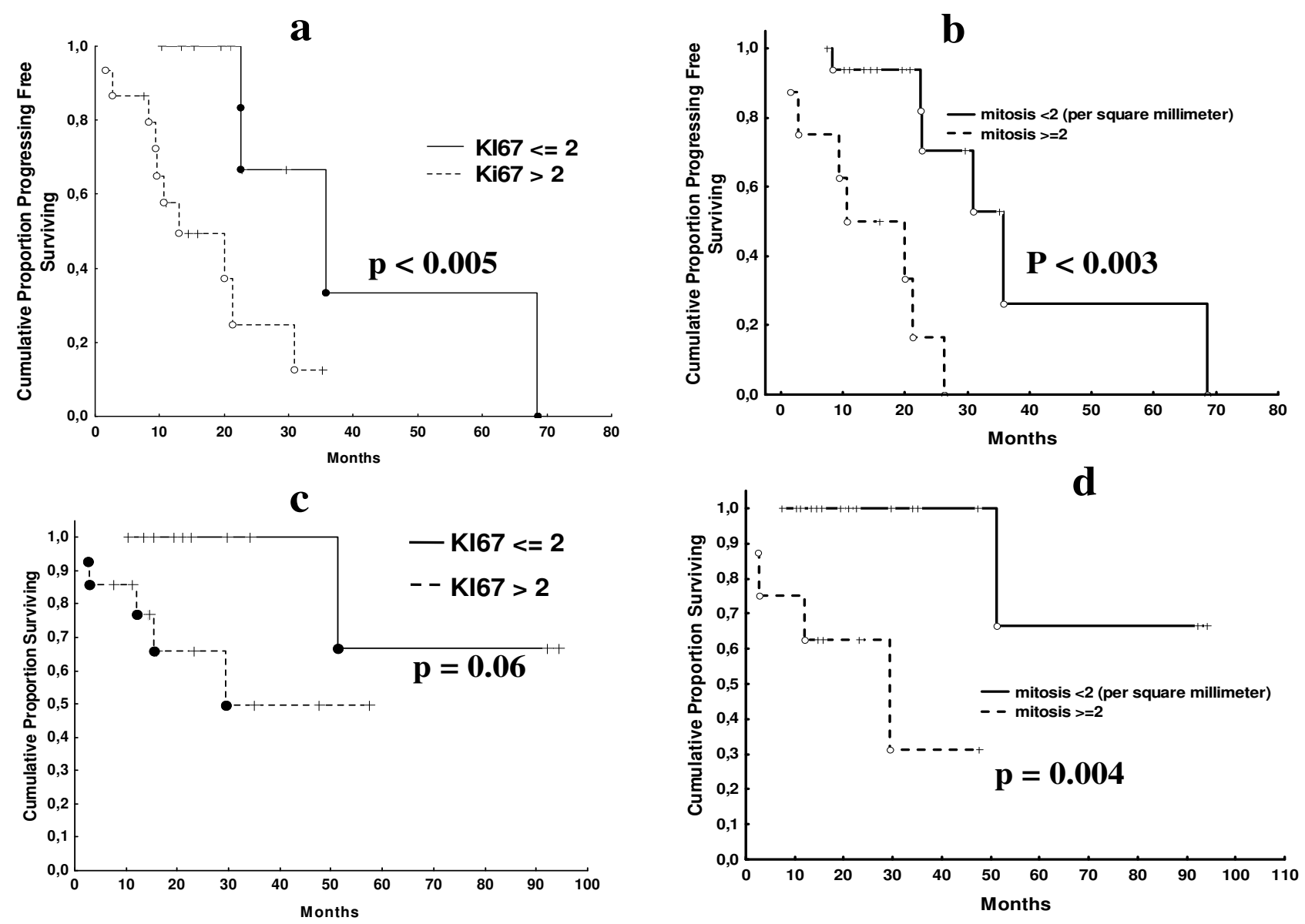

Figure I

Time to progression ( I a and Ib) and overall survival (Ic and Id) according to Ki67 expression at the cutoff of $2 \%$ positive cells and mitosis count.

a prolonging of disease stabilization. The potentiality of continuous 5FU in inducing tumor shrinkage could improve the efficacy of systemic treatment, a finding that needs to be assessed in a randomized study.

Due to the potential dedifferentiation of neuroendocrine carcinomas as a consequence of progression, it is expected that response to treatment in metastatic sites may differ from that of primary lesions. Our series was homogeneous in this respect, since 27 out of 29 patients had metastatic disease. Tumor shrinkage (partial response or minimal response) obtained by our regimen made surgery for residual disease (with/without liver chemoembolization or liver radiofrequency ablation) feasible in 3 patients. Surgery for residual disease seemed to be efficacious, since 2 patients were disease free at the last followup examination after 27 and 35 months, respectively.
In order to verify study population homogeneity, the tumor samples were centrally reviewed by two pathologists. Central review also allowed the pathologists to assess the biological prognostic parameters. Significant outcome predictors were mitotic count and Ki67 proliferation index, both parameters being reciprocally correlated. Only Ki67, however, maintained an independent prognostic role in the multivariate analysis, confirming the importance of assessing this marker in these tumors $[27,28]$. Ki67 is also an essential parameter in the proposed grading system for foregut neuroendocrine tumors of the stomach, duodenum, and pancreas [29]. The proposed cutoff of $2 \%$ to discriminate G1 from G2 carcinomas was associated with better outcome, confirming a recent report [30]. Ki67 is also used as predictive marker of treatment response in clinical decision-making algorithms $[7,31]$. It has been suggested that neuroendocrine 
carcinomas with high Ki67 expression may be potentially sensitive to conventional chemotherapy, whereas tumors with lower Ki67 expression may not [31]. This trend was confirmed in our series but failed to attain statistical significance.

It has been suggested that metronomic chemotherapy has antiangiogenetic activity [10]. The activity of metronomic chemotherapy in reducing circulating VEGF levels was observed in a previous study in patients with advanced breast cancer [32]. In the present study, plasma VEGF levels monitored every 3 months in 11 patients showed a stepwise reduction over time that failed to attain statistical significance due to the small sample size. On an individual basis, however, 7 patients were noted to have a decrease in VEGF and only 2 an increase. Taken together, these data evince an antiangiogenic effect of continuous 5FU plus octreotide treatment.

In a recent Italian multicenter study, a combination of oxaliplatin and metronomic capecitabine (an oral 5FU analogue) was administered to 40 patients with malignant neuroendocrine tumors. Interestingly, a disease response was observed in 23\% of patients with high-grade and in $30 \%$ of those with low-grade neuroendocrine tumors, respectively [33]. The introduction of metronomic capecitabine could account for the high response rate obtained in this well-differentiated subset.

Continuous 5FU infusion in this patient subset was well tolerated as most toxicities observed were mild (grade I or II). As expected, dose-limiting toxicities were non hematolological (mucositis, diarrhea, hand-foot syndrome) and delayed treatment in $40 \%$ of patients.

\section{Conclusion}

The combination of 5FU continuous infusion and LAR octreotide is an active regimen in the treatment of metastatic well-differentiated neuroendocrine carcinomas and may have antiangiogenic activity. The potential synergism between metronomic chemotherapy and antiangiogenic drugs provides a rationale for exploring this association in the future. Moreover, capecitabine is an orally available 5FU derivative found to have the same efficacy as continuous 5FU infusion in patients with advanced colon carcinoma. Capecitabine administered on a metronomic schedule instead of 5FU infusion should be tested in patients with advanced neuroendocrine carcinoma, thus obviating the need for an implantable central venous access.

\section{Competing interests}

The authors declare that they have no competing interests.

\section{Authors' contributions}

BMP and BA were critically involved in the study design, statistical analysis, and drafting of the manuscript. DL and BO conceived of the study, participated in designing the study and assisted in drafting the manuscript. VM and PM carried out the immunohistochemical analysis and the central histological review. $\mathrm{CF}, \mathrm{BN}, \mathrm{BS}, \mathrm{PD}, \mathrm{FB}, \mathrm{AO}, \mathrm{CL}$ participated in primer selection, attended to patients, and revised the methods section of the manuscript. FA and $\mathrm{ME}$ were involved in data collection. All authors have read and approved the final manuscript.

\section{Acknowledgements}

This study was supported by a grant from the MIUR (Ministero dell'Istruzione, dell'Università e della Ricerca)

\section{References}

I. Solcia E, Kloppel G, Sobhin LH: Histological typing of endocrine tumours. Springer-Verlag: New York; 2000.

2. Faiss S, Pape UF, Bohmig M, Dorffel Y, Mansmann U, Golder W, Riecken EO, Wiedenmann B: International Lanreotide and Interferon Alfa Study Group. Prospective, randomized, multicenter trial on the antiproliferative effect of lanreotide, interferon alfa, and their combination for therapy of metastatic neuroendocrine gastroenteropancreatic tumors--the International Lanreotide and Interferon Alfa Study Group. J Clin Oncol 2003, 21:2689-2696.

3. Modlin IM, Lye KD, Kidd M: A 5-decade analysis of 13,7 I5 carcinoid tumors. Cancer 2005, 5,97(4):934-59.

4. Oberg K, Kvols L, Caplin M, Delle Fave G, de Herder W, Rindi G, Ruszniewski $\mathrm{P}$, Woltering EA, Wiedenmann B: Consensus report on the use of somatostatin analogs for the management of neuroendocrine tumors of the gastroenteropancreatic system. Ann Oncol 2004, I 5:966-973.

5. Hejna M, Schmidinger M, Raderer M: The clinical role of somatostatin analogues as antineoplastic agents: much ado about nothing? Ann Oncol 2000, 13:653-668.

6. Oberg K: Neuroendocrine gastrointestinal tumors - a condensed overview of diagnosis and treatment. Ann Oncol 1999, I0(S2):S3-8.

7. Oberg K: Neuroendocrine tumors of the gastrointestinal tract: recent advances in molecular genetics, diagnosis, and treatment. Curr Opin Oncol 2005, 17:386-391.

8. Pavel ME, Baum U, Hahn EG, Hensen J: Doxorubicin and streptozotocin after failed biotherapy of neuroendocrine tumors. Int J Gastrointest Cancer 2005, 35: 179-185.

9. Sun W, Lipsitz S, Catalano P, Mailliard JA, Haller DG: Phase II/III study of doxorubicin with fluorouracil compared with streptozocin with fluorouracil or dacarbazine in the treatment of advanced carcinoid tumors: Eastern Cooperative Oncology Group study EI 28I. J Clin Oncol 2005, 22:4897-4904.

10. Kerbel RS, Kamen BA: The anti-angiogenic basis of metronomic chemotherapy. Nat Rev Cancer 2004, 7,4(6):423-36.

II. Vacca A, lurlaro M, Ribatti D, Minischetti M, Nico B, Ria R, Pellegrino $A$, Dammacco $F$ : Antiangiogenesis is produced by non toxic doses of vinblastine. Blood 1999, 94:4|43-4I55.

12. Rozados VR, Sànchez AM, Gervasoni SI, Berra HH, Matar P, Graciela Scharovsky O: Metronomic therapy with cyclophosphamide induces rat lymphoma and sarcoma regression and is devoid of toxicity. Ann Oncol 2004, 15:1543-1550.

13. Bottini A, Generali D, Brizzi MP, Fox SB, Bersiga A, Bonardi S, Allevi G, Aguggini S, Bodini G, Milani M, Dionisio R, Bernardi C, Montruccoli A, Bruzzi P, Harris AL, Dogliotti L, Berruti A: Randomized phase II trial of letrozole and letrozole plus low-dose metronomic oral cyclophosphamide as primary systemic treatment in elderly breast cancer patients. J Clin Oncol 2006, 24(22):3623-8.

14. Couvelard A, O'Toole D, Turley H, Leek R, Sauvanet A, Degott C, Ruszniewski P, Belghiti J, Harris AL, Gatter K, Pezzella F: Microvascular density and hypoxia-inducible factor pathway in pancreatic endocrine tumours: negative correlation of 
microvascular density and VEGF expression with tumour progression. $\mathrm{Br} J$ Cancer 2005, 92:94-I0I.

15. Phan AT, Wang L, Xie K, Zhang J, Rashid A, Evans D, Vauthey J, Abdalla E, Abbruzzese JL, Yao JC: Association of VEGF expression with poor prognosis among patients with low-grade neuroendocrine carcinoma. J Clin Oncol 2006. ASCO Annual Meeting Proceedings Part I. Vol 24, No. I8S (June 20 Supplement), abs 4091.

16. Kulke MH, Stuart K, Earle C, Bhargava P, Clark JW, Enzinger PC, Meyerhardt J, Attawia M, Lawrence C, Fuchs CS: A phase II study of temozolomide and bevacizumab in patients with advanced neuroendocrine tumors. J Clin Oncol 2006. ASCO Annual Meeting Proceedings Part I. Vol 24, No. I8S (June 20 Supplement), abs 4044.

17. Moertel C, Lefkopoulo M, Lipsitz S, Hahn R, Klaassen D: Streptozocin-doxorubicin, streptozocin-fluorouracil, or chlorozotocin in the treatment of advanced islet-cell carcinoma. N Engl J Med 1992, 326:519-523.

18. Hughes MJ, Kerr DJ, Cassidy J, Soukop M, McGregor K, Blackburn N, Yosef $H$, Kaye SB: A pilot study of combination therapy with interferon- $\alpha-2 a$ and 5 -fluorouracil in metastatic carcinoid and malignant endocrine pancreatic tumours. Ann Oncol 1996, 7:208-210.

19. Papamichael D, Seymour MT, Penson RT, Wilson P, Gallagher CJ, Besser GM, Slevin ML: Double modulation of 5-fluorouracil with Interferon alpha-2a and high-dose leucovorin in advanced neuroendocrine tumours. Eur J Cancer 1998, 34(I3):2 I33-2 I 34

20. Andreyev HJN, Scott-Mackie P, Cunningham D, Nicolson V, Norman AR, Badve SS, Iveson A, Nicolson MC: Phase II study of continuous infusion fluorouracil and interferon alfa-2b in the palliation of malignant neuroendocrine tumors. J Clin Oncol 1995, | 3:| |486-|492.

21. Weckbecker G, Raulf F, Tolcsvai L, Bruns C: Potentiation of the anti-proliferative effects of anti-cancer drugs by octreotide in vitro and in vivo. Digestion 1996, 57(SI):22-8.

22. Trotti $A$, Colevas AD, Setser A, Rusch $V$, Jaques D, Budach $V$, Langer C, Murphy B, Cumberlin R, Coleman CN, Rubin P: CTCAE v3.0: development of a comprehensive grading system for the adverse effects of cancer treatment. Semin Radiat Oncol 2003, 13:176-181.

23. Therasse P, Arbuck SG, Eisenhauer EA, Wander J, Kaplan RS, Rubinstein L, Verweij J, Van Glabbeke M, van Oosterom AT, Christian MC, Gwyther SG: New guidelines to evaluate the response to treatment in solid tumors. European Organization for Research and Treatment of Cancer, National Cancer Institute of Canada. J Natl Cancer Inst 2000, 92:205-216.

24. Simon R: Optimal two-stage designs for phase II clinical trials. Control Clin Trials 1989, 10: I-10.

25. Arnold R, Simon B, Wied M: Treatment of neuroendocrine GEP tumours with somatostatin analogues. A review. Digestion 2000, 62(SI):84-9I.

26. Arnold R, Muller H, Schade-Brittinger C, Rinke A, Klose K, Barth P, Wied M, Mayer C, Aminossadati B, PROMID study group: Placebocontrolled, double-blind, prospective, randomized study of the effect of octreotide LAR in the control of tumor growth in patients with metastatic neuroendoccrine midgut tumors: A report from the PROMID study group. I Clin Oncol 2009, 27:15S.

27. Aparicio T, Ducreux M, Baudin E, Sabourin JC, De Baere T, Mitry E, Schlumberger M, Rougier P: Antitumour activity of somatostatin analogues in progressive metastatic neuroendocrine tumours. Eur J Cancer 2001, 37:1014-1019.

28. Butturini G, Bettini R, Missiaglia E, Mantovani W, Dalai I, Capelli P, Ferdeghini M, Pederzoli P, Scarpa A, Falconi M: Predictive factors of efficacy of the somatostatin analogue octreotide as first line therapy for advanced pancreatic endocrine carcinoma. Endocr Relat Cancer 2006, 13:1213-1221.

29. Rindi G, Kloppel G, Ahlmann H, Caplin M, Couvelard A, de Herder WW, Erikssson B, Falchetti A, Falconi M, Komminoth P, Körner M, Lopes JM, McNicol AM, Nilsson O, Perren A, Scarpa A, Scoazec JY, Wiedenmann B, all other Frascati Consensus Conference participants; European Neuroendocrine Tumor Society (ENETS): TNM staging of foregut (neuro)endocrine tumors: a consensus proposal including a grading system. Virchows Arch 2006, 449:395-40I.

30. Pape UF, Jann H, Müller-Nordhorn J, Bockelbrink A, Berndt U, Willich SN, Koch M, Röcken C, Rindi G, Wiedenmann B: Prognostic rele- vance of a novel TNM classification system for upper gastroenteropancreatic neuroendocrine tumors. Cancer 2008, I 1 3:256-65.

31. Oberg K: Management of neuroendocrine tumors. American Society of Clinical Oncology (ASCO) 2002 Educational Book, 38th Annual Meeting, J Clin Oncol 2008:40 I-405.

32. Colleoni M, Rocca A, Sandri MT, Zorzino L, Masci G, Nolè F, Peruzzotti G, Robertson C, Orlando L, Cinieri S, de BF, Viale G, Goldhirsch $A$ : Low-dose oral methotrexate and cyclophosphamide in metastatic breast cancer: Antitumor activity and correlation with vascular growth factor levels. Ann Oncol 2002, 13:73-80.

33. Bajetta E, Catena L, Procopio G, De Dosso S, Bichisao E, Ferrari L, Martinetti A, Platania M, Verzoni E, Formisano B, Bajetta R: Are capecitabine and oxaliplatin (XELOX) suitable treatments for progressing low-grade and high-grade neuroendocrine tumours? Cancer Chemother Pharmacol 2007, 59:637-642.

\section{Pre-publication history}

The pre-publication history for this paper can be accessed here:

http://www.biomedcentral.com/1471-2407/9/388/pre pub

Publish with Bio Med Central and every scientist can read your work free of charge

"BioMed Central will be the most significant development for disseminating the results of biomedical research in our lifetime. "

Sir Paul Nurse, Cancer Research UK

Your research papers will be:

- available free of charge to the entire biomedical community

- peer reviewed and published immediately upon acceptance

- cited in PubMed and archived on PubMed Central

- yours - you keep the copyright 